\title{
siRNA-mediated knockdown of ID1 disrupts Nanog- and Oct-4-mediated cancer stem cell-likeness and resistance to chemotherapy in gastric cancer cells
}

\author{
LINLIN LI $^{1^{*}}$, XIAOYONG WEI $^{2 *}$, BAOFENG WU $^{2}$, YUANLI XIAO ${ }^{3}$, MINGZHU YIN $^{4}$ and QIAOHONG YANG ${ }^{2,4}$ \\ ${ }^{1}$ Cancer Research Institute, Southern Medical University, Guangzhou, Guangdong 510515; \\ ${ }^{2}$ School of Basic Medical Sciences, Guangzhou University of Chinese Medicine, Guangzhou, Guangdong 510006; \\ ${ }^{3}$ Department of Gastroenterology, Pingdingshan Second People's Hospital, Pingdingshan, Henan 467000, \\ P.R. China; ${ }^{4}$ Department of Pathology, Yale University School of Medicine, New Haven, CT 06520, USA
}

Received August 20, 2015; Accepted November 7, 2016

DOI: $10.3892 / \mathrm{ol} .2017 .5828$

\begin{abstract}
DNA-binding protein inhibitor ID-1 (ID1) serves an essential role in tumor progression, and the self-renewal and pluripotency of embryonic stem cells. However, the effect of ID1 on the stemness and cancer stem cell (CSC)-like properties of gastric adenocarcinoma cells remains to be elucidated. In the present study, effective ID1 knockdown was achieved in gastric cancer (GC) cells using small interfering RNA, and the self-renewal ability and cisplatin (DDP) sensitivity of GC cells was subsequently examined. ID1 knockdown in the MKN-28 and MGC-803 cell lines was demonstrated to significantly suppress colony formation $(\mathrm{P}=0.005$ in $\mathrm{MKN}-28$ and $\mathrm{P}=0.001$ in MGC-803), tumor spheroid formation $(\mathrm{P}=0.021$ in $\mathrm{MKN}-28$ and $\mathrm{P}=0.037$ in $\mathrm{MGC}-803$ ), cell proliferation $(\mathrm{P}=0.028$ in $\mathrm{MKN}-28$ and $\mathrm{P}=0.001$ in $\mathrm{MGC}-803)$ and migration $(\mathrm{P}=0.002$ in $\mathrm{MKN}-28$ and $\mathrm{P}=0.015$ in $\mathrm{MGC}-803)$. To the best of our knowledge, the present study revealed for the first time that ID1 knockdown suppresses the expression of the key CSC-associated factors Nanog and octamer-binding protein 4 (Oct-4). It was further demonstrated that ID1 knockdown
\end{abstract}

Correspondence to: Dr Qiaohong Yang, School of Basic Medical Sciences, Guangzhou University of Chinese Medicine, 232 Outer Ring East Road, Guangzhou, Guangdong 510006, P.R. China E-mail: qiaohong_yang@yahoo.com

Dr Mingzhu Yin, Department of Pathology, Yale University School of Medicine, 333 Cedar Street, New Haven, CT 06520, USA

E-mail: mingzhu.yin@yale.edu

"Contributed equally

Abbreviations: GC, gastric cancer; HLH, helix-loop-helix; CSC, cancer stem cell; DDP, cisplatin; ESC, embryonic stem cell; EMT, epithelial-to-mesenchymal transition

Key words: DNA-binding protein inhibitor ID-1, gastric carcinoma, self-renewal, cancer stem cell-like properties, Nanog, cisplatin-resistant sensitized GC cells to DDP. In conclusion, knockdown of ID1 attenuates the stem cell like-properties of self-renewal in normal GC cells, potentially through the targeting of Nanog and Oct-4, and subsequently decreases cell proliferation and resistance to DDP. The results of the present study suggest that ID1 functions as an oncogene in GC and regulates the stem cell like-properties of gastric cancer cells by targeting Nanog and Oct-4.

\section{Introduction}

Globally, the incidence of gastric cancer (GC) ranks fourth in males and fifth in females worldwide; however, GC is the second leading cause of cancer-associated mortality globally (1). The developing world accounts for $70 \%$ of GC-associated mortalities worldwide, with China accounting for $\sim 40 \%$ of this (1). Infection with Helicobacter pylori, a microbial species that specifically colonizes the gastric epithelium, is the most well-known risk factor for developing GC, conferring an increased risk of $\sim 75 \%$ (2). Surgical intervention using endoscopy is a typical approach in the treatment of patients with early GC, achieving improved long-term outcomes (3). Postoperative adjuvant chemoradiation combined with several molecularly targeted drugs, including anti-vascular endothelial growth factor receptor 2 monoclonal antibodies and epidermal growth factor receptor $1 /$ receptor tyrosine-protein kinase erbB-2 inhibitors, is able to prolong relapse-free survival in patients with advanced GC (4). In order to overcome the limitations of GC therapy, determination of the drivers that contribute to GC tumorigenesis and malignancy is required.

The DNA-binding protein inhibitor ID (ID) subfamily, first cloned in 1900, belongs to the helix-loop-helix (HLH) class V family of transcription factors and contains four members in vertebrates; ID1, ID2, ID3 and ID4 $(5,6)$. The ubiquitous HLH class $\mathrm{V}$ family contains transcription factors that regulate cell fate, differentiation and proliferation, and are characterized by a highly conserved HLH domain adjacent to the $\mathrm{E}$ box DNA-binding region (7). The $\mathrm{E}$ box is present in the majority of HLH proteins and facilitates binding to DNA, except in the ID subfamily. ID proteins function predominantly as negative 
regulators of basic HLH (bHLH) transcription factors by forming ID-bHLH heterodimers (6). ID-bHLH heterodimers are unable to bind to DNA as they lack a DNA-binding region, leading to the subsequent inhibition of bHLH-mediated transcription (8).

ID1 is primarily expressed in embryonic stem cells (ESCs) and progenitor cells, and is downregulated in mature differentiated cells; however, ID1 expression is reactivated in numerous cancer cells (9). Although ID1 possesses opposing oncogenic and tumor suppressive functions, increased ID1 protein expression has been identified in the majority of tumor types, including bladder, breast, colorectal, esophageal and gastric (10-13). Aberrant ID1 protein expression in cancer is typically induced by oncoproteins, including Myc proto-oncogene protein (Myc), Ras GTPases, proto-oncogene tyrosine-protein kinase Src, neurogenic locus notch homolog proteins and growth factor signals, such as epidermal growth factor (EGF) (14-17). ID1 protein expression is typically repressed by tumor suppressor proteins, including forkhead box protein $\mathrm{O} 3$ and cellular tumor antigen p53 (p53) (18,19). ID1 serves critical roles in cell proliferation, epithelial-to-mesenchymal transition (EMT) and chemoresistance in various types of cancer (20).

ID1 is known to be an inhibitor of cellular differentiation and serves an essential role in the maintenance of ESC self-renewal and pluripotency (21). In an $\mathrm{ID}^{-/-}$murine model, hematopoietic whole bone marrow cells exhibited a decreased ability to self-renewal compared with a wild-type control (22). Similarly, another study demonstrated that self-renewal was increased in murine cortical neural stem cells following overexpression of ID1 (23). In colon cancer stem cells (CSCs), increased levels of ID1 are necessary for the acquisition of the CSC phenotype (24). Consistent with these findings, glioma cells expressing increased levels of ID1 exhibited increased self-renewal compared with glioma cells expressing decreased levels of ID1 (25). However, the role of ID1 in GC cell self-renewal and CSC-likeness remains to be elucidated. As ID1 serves an essential role in somatic stem cell self-renewal, the present study aimed to investigate the role of ID1 in GC tumorigenesis and CSC-likeness.

In the present study, ID1 was successfully knocked down in MGC-803, MKN-28 and SGC-7901 cells using small interfering (si) RNA, which led to impaired proliferation, migration and cell cycle progression in GC cells. ID1 knockdown was demonstrated to suppress GC cell self-renewal and CSC-like properties through the downregulation of Nanog and Oct-4, which established an association between the expression of ID1 and CSC-related transcription factors Nanog and octamer-binding protein 4 (Oct-4) in GC cells. In addition, it was demonstrated that ID1 depletion induces sensitivity to cisplatin (DDP) in GC cells, thus providing a novel therapeutic target for the treatment of GC.

\section{Materials and methods}

Cell culture and reagents. The GC cell lines, MKN-28, MGC-803 and SGC-7901 were purchased from the Laboratory Animal Center of Sun Yat-sen University Cell Bank (Guangzhou, China). MKN-28 is derived from MKN-74 (http://cellbank.nibiohn.go.jp/ cellbank/en/search_res_det. cgi?ID=340). Cells were grown in RPMI-1640 medium
(Gibco; Thermo Fisher Scientific, Inc., Waltham, MA, USA) supplemented with $10 \%$ fetal bovine serum (FBS; cat. no. 04-001-1A; Biological Industries, Beit-Haemek, Israel) at $37^{\circ} \mathrm{C}$ in a humidified atmosphere containing $5 \% \mathrm{CO}_{2}$. The primary antibodies used in western blot analysis were as follows: Mouse anti-ID1 (1:1,000; cat. no. ab168256; Abcam, Cambridge, UK); mouse anti-Nanog (1:500; cat. no. sc-376915; Santa Cruz Biotechnology, Inc., Dallas, TX, USA); mouse anti-octamer-binding protein 4 (1:1,000; cat. no. 611203; BD Biosciences, San Jose, CA, USA); rabbit anti-cyclin D1 (1:1,000; cat. no. 2261-1; Epitomics, Burlingame, CA, USA); mouse anti-transcription factor SOX2 (Sox2; 1:500; cat. no. 561469; BD Biosciences); mouse anti- $\beta$-actin (1:1,000; cat. no. sc-47778; Santa Cruz Biotechnology, Inc., CA, USA); and mouse anti-GAPDH (1:3,000; cat. no. 60004-1-lg; Proteintech Group, Inc., Chicago, IL, USA). Mouse (cat. no. SA00001-1) or rabbit (cat. no. SA00001-2) immunoglobulin G horseradish peroxidase-conjugated secondary antibodies (both 1:10,000; Proteintech Group, Inc., Chicago, IL, USA) were obtained from the Proteintech Group, Inc. (both 1:3,000). DDP was purchased from Sigma-Aldrich (Merck Millipore, Darmstadt, Germany; cat. no. p4394).

siRNA transfection. ID1 knockdown was achieved by RNA interference using siRNA in the GC cell line MGC-803. The full-length ID1 mRNA sequence was retrieved from GenBank (NM_002165.3; www.ncbi.nlm.nih. gov/nuccore/NM_002165.3). The siRNA sequences were designed by Takara Biotechnology Co., Ltd., (Dalian, China) and synthesized by Invitrogen (Thermo Fisher Scientific, Inc.). The sequences of the ID1 and negative control (NC) siRNAs are shown in Table I. A total of 1 day prior to transfection, cells were seeded into a 6-well plate at a confluency of between 50 and $60 \%$. Cells in the logarithmic phase of growth were transfected with $100 \mathrm{nM}$ siRNA-ID1 or siRNA-NC in Opti-MEM ${ }^{\mathrm{TM}} \mathrm{I}$ Reduced Serum media using Lipofectamine ${ }^{\mathrm{TM}} 2000$ (both Thermo Fisher Scientific, Inc.), according to the manufacturer's protocol.

Reverse transcription-polymerase chain reaction (RT-PCR) analysis of IDI mRNA expression. The efficacy of siRNA transfection was evaluated using RT-PCR. A total of $48 \mathrm{~h}$ following transfection, total cellular RNA was extracted using TRIzol ${ }^{\circledR}$ reagent (Invitrogen; Thermo Fisher Scientific, Inc.), according to the manufacturer's protocol. First-strand cDNA was subsequently synthesized by denaturing $1 \mu \mathrm{g}$ RNA at $65^{\circ} \mathrm{C}$ for $10 \mathrm{~min}$ with $0.1 \mu \mathrm{g}$ oligo-dT (Takara Biotechnology Co., Ltd.) and the denatured product was immediately incubated in an ice bath for $5 \mathrm{~min}$. The denatured product was made up to a total volume of $25 \mu \mathrm{l}$ with the addition of $1 \mu \mathrm{l}$ dNTP (10 mM/base; cat. no. U1205), 100 units RNasin ${ }^{\circledR}$ Ribonuclease inhibitor (cat. no. N2111), 10 units Moloney murine leukemia virus reverse transcriptase (cat. no. M1701) (all Promega Corporation, Madison, WI, USA) and 0.01\% diethylpyrocarbonate (DEPC; cat. no. 472565; Sigma-Aldrich; Merck Millipore) in $\mathrm{H}_{2} \mathrm{O}$. The mix was incubated at $42^{\circ} \mathrm{C}$ for $60 \mathrm{~min}$, $95^{\circ} \mathrm{C}$ for $5 \mathrm{~min}$ and then on ice for $3 \mathrm{~min}$ prior to being stored at $-20^{\circ} \mathrm{C}$ until the cDNA template was required for PCR. Primers targeting ID1 and $\beta$-actin were designed using Premier Primer software (version 5.0; Premier Biosoft International, Palo Alto, 
CA, USA) and synthesized by Invitrogen (Thermo Fisher Scientific, Inc.). Primer sequences are shown in Table II. PCR was performed in a total reaction volume of $10 \mu 1$, containing $5 \mu 12$ X Taq PCR Master Mix (cat. no. K0171; Thermo Fisher Scientific Inc.), $0.25 \mu \mathrm{l}$ forward primer $(10 \mu \mathrm{M}), 0.25 \mu \mathrm{l}$ reverse primer $(10 \mu \mathrm{M}), 0.5 \mu \mathrm{l}$ of template cDNA $(200 \mathrm{ng} / \mu \mathrm{l})$ and DEPC-treated water (cat. no. R0021; Beyotime Institute of Biotechnology, Haimen, China). PCR thermocycling conditions were as follows: $94^{\circ} \mathrm{C}$ for $5 \mathrm{~min} ; 30$ cycles of $94^{\circ} \mathrm{C}$ for $30 \mathrm{sec}, 62^{\circ} \mathrm{C}$ for $30 \mathrm{sec}$ and $72^{\circ} \mathrm{C}$ for $1 \mathrm{~min}$; and $72^{\circ} \mathrm{C}$ for $7 \mathrm{~min}$. Agarose gel electrophoresis was performed on the final PCR products using a $2 \%$ agarose gel containing $0.5 \mu \mathrm{g} / \mu \mathrm{l}$ ethidium bromide, and images were captured using the Tanon-4100 Gel Imaging system (Tanon Science and Technology Co., Ltd., Shanghai, China). The expression of ID1 mRNA normalized to $\beta$-actin was determined using Image-Pro ${ }^{\circledR}$ Plus software (version 5.1; Rockville, MD, USA).

Cell viability assay and 5-ethynyl-2'-deoxyuridine (EdU) analysis. The Cell Counting Kit-8 (CCK-8; cat. no. BB-4202; BestBio Co., Shanghai, China) assay was used to evaluate the viability of MKN-28 and MGC-803 cells. Between 2,000 and 3,000 GC cells/well were seeded into a 96-well plate and subsequently transfected with siRNA-ID1 or siRNA-NC for 24,48 and $72 \mathrm{~h}$, as described above. A total of $10 \mu \mathrm{l} \mathrm{CCK}-8$ reagent was added to each well and plates were incubated for $1 \mathrm{~h}$ at $37^{\circ} \mathrm{C}$ prior to measuring the absorbance at $450 \mathrm{~nm}$ using the ELx800 ${ }^{\mathrm{TM}}$ Absorbance Reader (BioTek Instruments, Inc., Winooski, VT, USA). The Cell-Light ${ }^{\mathrm{TM}}$ EdU Apollo ${ }^{\circledR} 567$ In Vitro Imaging kit (cat. no. C10310; RiboBio Co., Ltd., Guangzhou, China) was used to label cells in the $\mathrm{S}$ phase based on EdU labeling as previously described (25). According to the manufacturer's protocol, siRNA-transfected cells were incubated with EdU solution for $3 \mathrm{~h}$ at $37^{\circ} \mathrm{C}$. Cells were subsequently washed with PBS, fixed with $4 \%$ paraformaldehyde for $30 \mathrm{~min}$, and permeated using $0.5 \%$ Triton $^{\mathrm{TM}}$ X-100. Apollo567 from the Imaging kit and DAPI (Sigma-Aldrich; Merck Millipore) were used for EdU and nuclear staining, respectively. Images were captured using a fluorescence microscope (Eclipse Ti-U inverted microscope; Nikon Corporation, Tokyo, Japan). EdU-positive cells were counted using Image Pro Plus software (version 6.0; Media Cybernetics, Rockville, MD, USA).

Flow cytometric analysis of cell cycle distribution and apoptosis. Following transfection with si-ID1 or si-NC, MKN-28 and MGC-803 cells $\left(2 \times 10^{6}-5 \times 10^{6}\right)$ were harvested using trypsin and resuspended in $300 \mu \mathrm{l}$ PBS. The cell suspension was subsequently incubated in $700 \mu \mathrm{l}$ ice-cold absolute ethanol overnight at $4^{\circ} \mathrm{C}$. Cells were pelleted through centrifugation at $13,400 \times \mathrm{g}$ at $4^{\circ} \mathrm{C}$ for $5 \mathrm{~min}$, and then washed with PBS, prior to resuspension in PBS containing $100 \mu \mathrm{g} / \mathrm{ml}$ RNase inhibitor and $25 \mu \mathrm{g} / \mathrm{ml}$ propidium iodide (PI). The mixture was incubated in an ice bath for $30 \mathrm{~min}$ prior to flow cytometric analysis of cell cycle distribution using the BD FACSCalibur flow cytometer (BD Biosciences, Franklin Lakes, NJ, USA). The fractions of cells in $\mathrm{G}_{0} / \mathrm{G}_{1}, \mathrm{~S}$, and $\mathrm{G}_{2} / \mathrm{M}$ phases were analyzed using FlowJo software (version 7.6.2; Tree Star, Inc., Ashland, OR, USA).

The apoptotic rates of MKN-28 and MGC-803 cells were analyzed using the Annexin V-fluorescein isothiocyanate
(FITC) Apoptosis Detection kit (Nanjing KeyGen Biotech Co., Ltd., Nanjing, China), according to the manufacturers' protocol. Briefly, between $2 \times 10^{6}$ and $5 \times 10^{6}$ transfected cells were harvested using trypsin, and resuspended in $500 \mu \mathrm{l}$ binding buffer containing $5 \mu \mathrm{l}$ Annexin V-FITC from the Apoptosis Detection kit, and $5 \mu \mathrm{l}$ PI. The mix was incubated for $15 \mathrm{~min}$ at $4^{\circ} \mathrm{C}$ prior to flow cytometric analysis using the BD FACSCalibur flow cytometer (BD Biosciences, Franklin Lakes, NJ, USA).

Western blot analysis. A total of $48 \mathrm{~h}$ following siRNA transfection, MKN-28 and MGC-803 cells were harvested and lysed in 1X radioimmunoprecipitation assay buffer (cat. no. P0013B; Beyotime Institute of Biotechnology) containing phenylmethylsulfonyl fluoride (cat. no. ST506; Beyotime Institute of Biotechnology) and a phosphatase inhibitor cocktail (cat. no. CW2383; CW Biotech, Beijing, China). Proteins (100 ng/lane) were separated on a $10 \%$ (for protein with a mass of $40-170 \mathrm{kDa}$ ) or $12 \%$ (for protein with a mass of $15-70 \mathrm{kDa}$ ) gel through SDS-PAGE. Proteins were subsequently transferred onto a polyvinylidene difluoride membrane (EMD Millipore, Billerica, MA, US) and blocked with $5 \%$ bovine serum albumin (Beyotime Institute of Biotechnology). The membrane was subsequently incubated overnight at $4^{\circ} \mathrm{C}$ with the following primary antibodies: Anti-ID1; anti-Nanog; anti-Sox 2; anti-Oct-4; anti-cyclin D1; and anti-GAPDH. The membrane was washed 4 times by TBS-Tween 20 buffer (6 min/wash), followed by treatment with secondary antibodies for $1 \mathrm{~h}$ at room temperature. Protein bands were visualized using the Enhanced Chemiluminescence Western Blot kit (cat. no. P90720; EMD Millipore). Relative protein expression analysis using Image Lab software (version 3.0.1 beta 1; Bio-Rad Laboratories, California, USA) was normalized to GAPDH or $\beta$-actin.

Colony formation assay. MKN-28 and MGC-803 cells were seeded into a 6 -well plate at a density of 500 cells/well and transfected with siRNA-ID1 or siRNA-NC the following day, as described above. The cells were subsequently cultured in RPMI-1640 medium containing 10\% FBS and re-transfected every 4 days for 2 weeks. In addition, certain cell groups were treated with $1 \mu \mathrm{g} / \mathrm{ml}$ DDP. Cell colonies were subsequently fixed with methanol and stained with crystal violet (Nanjing Jiancheng Bioengineering Institute, Nanjing, China). Visible colonies of $>50$ cells were counted by eye for each sample and colony formation rates were subsequently calculated as follows: Number of colonies/the number of cells seeded. Colony formation assays were performed in triplicate.

Tumor spheroid formation assay. A total of $10 \mathrm{~h}$ following transfection, GC cells were trypsinized, washed with PBS and seeded into a 6-well ultra-low attachment plate (Corning Life Sciences, Acton, MA, USA) at a density of $1 \times 10^{5}$ cells/well. Cells were cultured in serum-free Dulbecco's modified Eagle's medium: Nutrient mixture F-12 (Thermo Fisher Scientific, Inc.) supplemented with EGF, basic fibroblast growth factor and B27 (all 20 ng/ml; all Gibco; Thermo Fisher Scientific, Inc.). To study the effect of ID1 knockdown on tumor spheroid formation, transfections were repeated on the fourth day. Following 8 days of incubation at $37^{\circ} \mathrm{C}$, images were captured 
using a fluorescence microscope (Eclipse Ti-U inverted microscope). Tumor spheroids with a diameter of $>20 \mu \mathrm{m}$ were counted using ImageJ software (version 1.37; National Institutes of Health, Bethesda, MD, USA). Data are presented as the number of spheroids in 5 randomly selected fields and are the result of triplicate experiments (26).

Cell migration assay. Cell migration assays were performed using a 24-well Transwell ${ }^{\circledR}$ Chamber (Corning Life Sciences), according to the manufacturer's protocol. MKN-28 and MGC-803 cells were harvested $24 \mathrm{~h}$ following siRNA transfection and resuspended in serum-free RPMI-1640 medium. Cells were seeded into the upper chamber at a density of 200 cells/wells. RPMI-1640 medium containing 10\% FBS was added into the lower chambers and cells were incubated at $37^{\circ} \mathrm{C}$ for $12(\mathrm{MKN}-28)$ and 20 (MGC-803) h. Migratory cells were immobilized in methanol for $10 \mathrm{~min}$ and stained with Giemsa (Nanjing Jiancheng Bioengineering Institute), according to the manufacturer's protocol. Photomicrographs of 5 randomly selected fields were captured using a Nikon Eclipse Ti-U inverted microscope.

Statistical analysis. Data analysis was conducted using SPSS Statistics software (version 20.0; IBM SPSS, Armonk, NY, USA). All values are presented as the mean \pm standard error of the mean. A two-tailed Student's $t$-test was used to analyze differences between treatment groups in the cell proliferation, colony formation, cell migration, tumor spheroid formation and EdU assays. One-way analysis of variance was performed to compare differences between multiple groups for cell viability and apoptosis analysis. $\mathrm{P}<0.05$ was considered to indicate a statistically significant difference. All experiments were repeated between 3 and 5 times.

\section{Results}

Evaluating the IDI knockdown efficiency of siRNA-IDI in MGC-803 cells. To study the effect of endogenous ID1 depletion in GC cells, four ID1-specific siRNAs, ID1-201, ID1-252, ID1-266 and ID1-316, were synthesized and transiently transfected into MGC-803 cells. The effect of the four siRNAs on ID1 mRNA and protein levels was determined in order to identify the most efficient siRNA. RT-PCR analysis was performed $48 \mathrm{~h}$ following transfection, as illustrated in Fig. 1. ID1 mRNA expression in si-ID1-transfected and si-NC-transfected cells was determined following normalization to $\beta$-actin. The ratio of ID1 to $\beta$-actin in the siRNA-NC-transfected group was arbitrarily set to 1.00 . Relative ID1 mRNA expression was decreased by $0.65,0.86$ and 0.95 times, following transfection with ID1-201, ID1-266 and ID1-316, respectively (Fig. 1C). By contrast, transfection with ID1-252 resulted in an increased relative ID1 mRNA expression of 1.73 times (Fig. 1C). These results indicate that ID-201 is the most effective siRNA, resulting in a significant decrease in ID1 mRNA expression $(\mathrm{P}=0.008$ vs. siRNA-NC; Fig. 1C). ID1 protein expression was detected using western blotting $72 \mathrm{~h}$ following siRNA transfection, thus allowing sufficient time for transcription. Transfection with ID1-201 and ID1-266 decreased ID1 protein expression, while transfection with ID1-252 and ID1-316 increased ID1 protein expression (Fig. 1D). Transfection with
ID1-201 significantly decreased ID1 protein expression (47\%; $\mathrm{P}=0.027$ vs. siRNA-NC; Fig. 1D). Transfection with ID1-201 produced a 1.53- and 1.88-fold reduction in ID1 mRNA and protein expression, respectively, and was therefore used for further investigation.

Effect of IDI knockdown on the proliferation and cell cycle distribution of MGC-803 and MKN-28 cells. ID1 has been reported to increase cell proliferation in several types of cancer, including glial, liver, colorectal and gastric (27-29); therefore, the effect of ID1 knockdown on proliferation and cell cycle distribution was investigated. The MGC-803 (poorly-differentiated) and MKN-28 (well-differentiated) gastric adenocarcinoma cell lines were used to evaluate the effect of ID1 knockdown on the proliferation of GC cells. From 2 days following transfection, MGC-803 and MKN-28 cells transfected with the siRNA-NC demonstrated significantly increased proliferation compared with the siRNA-ID1-transfected cells (MKN-28, P=0.009; MGC-803, P=0.003; Fig. 2A). EdU assays were used to analyze the proliferative ability of GC cells, as shown in Fig. 2B. A total of $48 \mathrm{~h}$ following transfection, siRNA-ID1-transfected MKN-28 cells exhibited a significant reduction in $\mathrm{S}$ phase EdU-labeling (21 to 13\%) compared with the siRNA-NC-transfected cells $(\mathrm{P}=0.028)$. In addition, siRNA-ID1-transfected MGC-803 cells exhibited a significant reduction in $\mathrm{S}$ phase EdU-labeling (37 to 19\%) compared with the siRNA-NC-transfected cells $(\mathrm{P}<0.001)$. Consistent with published data (29), these results indicate that siRNA-mediated ID1 knockdown inhibits GC cell growth.

Cell cycle dysfunction serves an essential role in the development of GC, therefore the effect of ID1 knockdown on cell cycle distribution in the MKN-28, MGC-803 and SGC-7901 cell lines was evaluated. As shown in Fig. 2C and $D$, the proportion of cells in the $G_{0} / G_{1}$ phases was significantly increased in the siRNA-ID1-transfected cells compared with the siRNA-NC-transfected cells, for all three cell lines $(\mathrm{P}=0.017)$. By contrast, the mean proportion of all three cell types in the $\mathrm{S}$ phase was significantly decreased in the siRNA-D1-transfected cells compared with the siRNA-NC-transfected cells ( $\mathrm{P}=0.018$; Fig. 2D). These results demonstrate that ID1 knockdown in GC cells results in $\mathrm{G}_{1}$ cell cycle arrest. Cyclin D1 is known to be the primary cyclin that couples to cyclin-dependent kinases $4 / 6$ and drives $\mathrm{G}_{1}$ to $\mathrm{S}$ phase cell cycle progression (30), therefore cyclin D1 protein expression was evaluated using western blotting. A decrease in cyclin D1 protein expression was observed in the ID1 knockdown cells (Fig. 2E). These results indicate that ID1 knockdown attenuates aberrant cell proliferation and leads to $\mathrm{G}_{1}$ cell cycle arrest, suggesting a role in GC cell growth and cell cycle progression.

ID1 knockdown leads to reduced CSC self-renewal in GC. CSCs form a rare cell population within cancer tissue, and exhibit self-renewal, differentiation potential and tumorigenic capacity (31). Nanog, Oct-4, Sox 2 and Krueppel-like factor 4 (KLF4) are key factors in stem cell reprogramming, and their interactions are involved in the maintenance of stem cell pluripotency and self-renewal. As ID1 is a known inhibitor of differentiation, the effect of ID1 knockdown on the stem cell like-properties of GC was examined. Colony formation is a 
Table I. Sequences of siRNA for ID1 knockdown.

siRNA sequence $\left(5^{\prime}-3^{\prime}\right)$

\begin{tabular}{lcc}
\cline { 2 - 3 } Name & \multicolumn{1}{c}{ Sense } & Antisense \\
\hline si-NC & UUC UCC GAA CGU GUC ACG UTT & ACG UGA CAC GUU CGG AGA ATT \\
ID1-201 & CGA CAU GAA CGG CUG UUA CTT & GUA ACA GCC GUU CAU GUC GTT \\
ID1-252 & AGA ACC GCA AGG UGA GCA ATT & UUG CUC ACC UUG CGG UUC UGG \\
ID1-266 & UGA GCA AGG UGG AGA UUC UTT & AGA AUC UCC ACC UUG CUC ATT \\
ID1-316 & GUU GGA GCU GAA CUC GGA ATT & UUC CGA GUU CAG CUC CAA CTG
\end{tabular}

ID1, DNA-binding protein inhibitor 1; si, small interfering; NC, negative control.

Table II. Primers used in reverse transcription-quantitative polymerase chain reaction analysis.

Primer sequence $\left(5^{\prime}-3^{\prime}\right)$

\begin{tabular}{llll}
\cline { 2 - 3 } Gene & \multicolumn{1}{c}{ Forward } & Reverse & Product length (bp) \\
\hline ID1 & ATCAGGGACCTTCAGTTGGAGC & AGACCCACAGAGCACGTAATTCC & 236 \\
$\beta$-actin & TAAAGACCTCTATGCCAACACAGT & CACGATGGAGGGGCCGGACTCATC & 240
\end{tabular}

ID1, DNA-binding protein inhibitor 1.

A



C



B

ID1 (236bp)

$\beta$-actin (236bp)

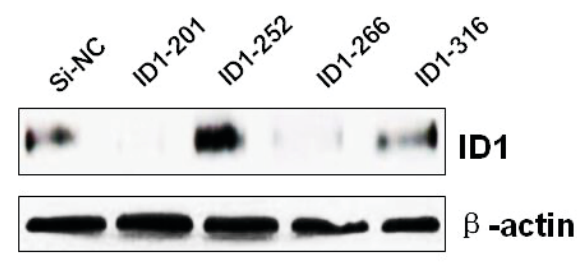

C

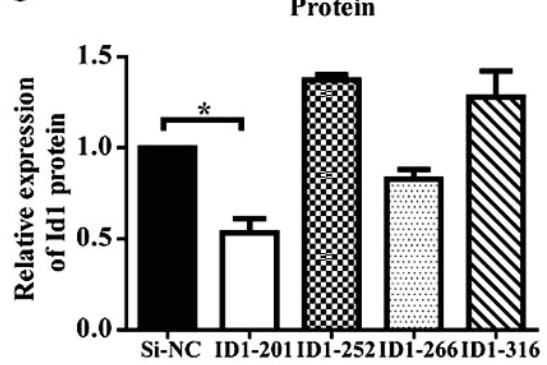

Figure 1. Evaluating the knockdown efficiency of si-ID1 in MGC-803 cells. MGC-803 cells were transiently transfected with 4 siRNAs targeting ID1 (ID-201, ID-252, ID-266 and ID-316, respectively) and compared to cells transfected with a negative control siRNA. (A) ID1 mRNA expression was analyzed using reverse transcription-polymerase chain reaction analysis. (B) ID1 protein expression was analyzed using western blot analysis. (C) Relative ID1 mRNA expression was semi-quantified and normalized to $\beta$-actin. (D) Relative ID1 protein expression was quantified and normalized to $\beta$-actin. Values are presented as the mean \pm standard deviation of triplicate results. ${ }^{*} \mathrm{P}<0.05,{ }^{* *} \mathrm{P}<0.01$ vs. si-NC-transfected cells. si-, small interfering RNA; NC, negative control; ID1, DNA-binding protein inhibitor ID-1.

distinct ability of CSCs in malignant tumors; therefore colony formation was analyzed in MGC-803 and MKN-28 cell lines following siRNA transfection. As shown in Fig. 3A, colony formation rates following ID1 knockdown were significantly reduced in MKN-28 (28 to 11\%) and MGC-803 (45 to 23\%) cells compared with the control cells $(\mathrm{MKN}-28, \mathrm{P}=0.005$; 
A

MKN-28


B $\frac{2}{\text { MKN-28 }}$
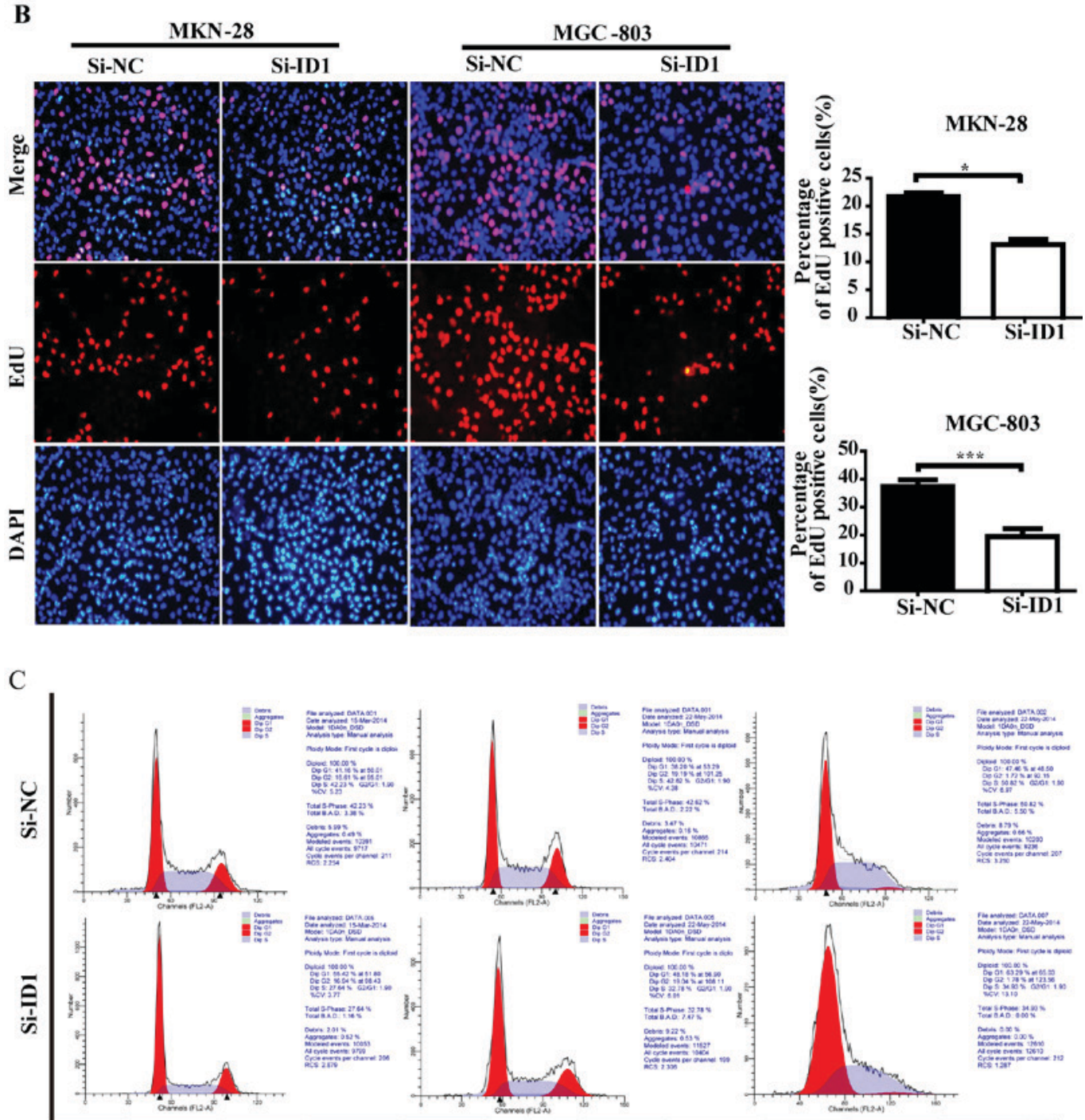

MKN-28

MGC-803

SGC-7901

D

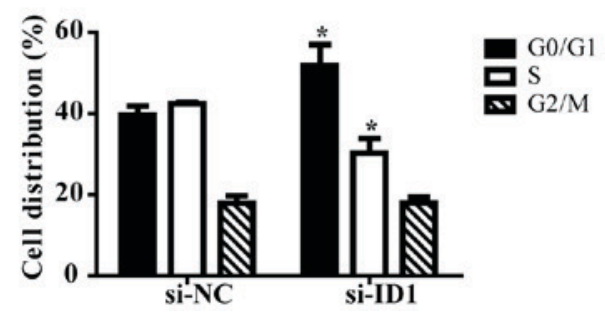

$\mathbf{E}$



Figure 2. Effect of ID1 knockdown on the proliferation and cell cycle distribution of gastric cancer cells. (A) Cell Counting Kit-8 evaluation of MKN-28 and MGC-803 cell proliferation, $48 \mathrm{~h}$ following transfection. (B) EdU assay evaluation of MKN-28 and MGC-803 cells in the S phase following si-NC and si-ID1 transfection. (C) Flow cytometric cell cycle analysis of MKN-28, MGC-803 and SGC-7901 cells following transfection. (D) Quantified cell cycle distribution following transfection. (E) Western blot analysis revealed decreased cyclin D1 protein expression following ID1 knockdown. Values are presented as the mean \pm standard deviation of triplicate results. ${ }^{*} \mathrm{P}<0.05,{ }^{* *} \mathrm{P}<0.01,{ }^{* * *} \mathrm{P}<0.001$ vs. si-NC-transfected cells. ID1, DNA-binding protein inhibitor ID-1; si-, small interfering RNA; NC, negative control; EdU, 5-ethynyl-2'-deoxyuridine; OD, optical density; FL, fluorescence; A, area. 



C
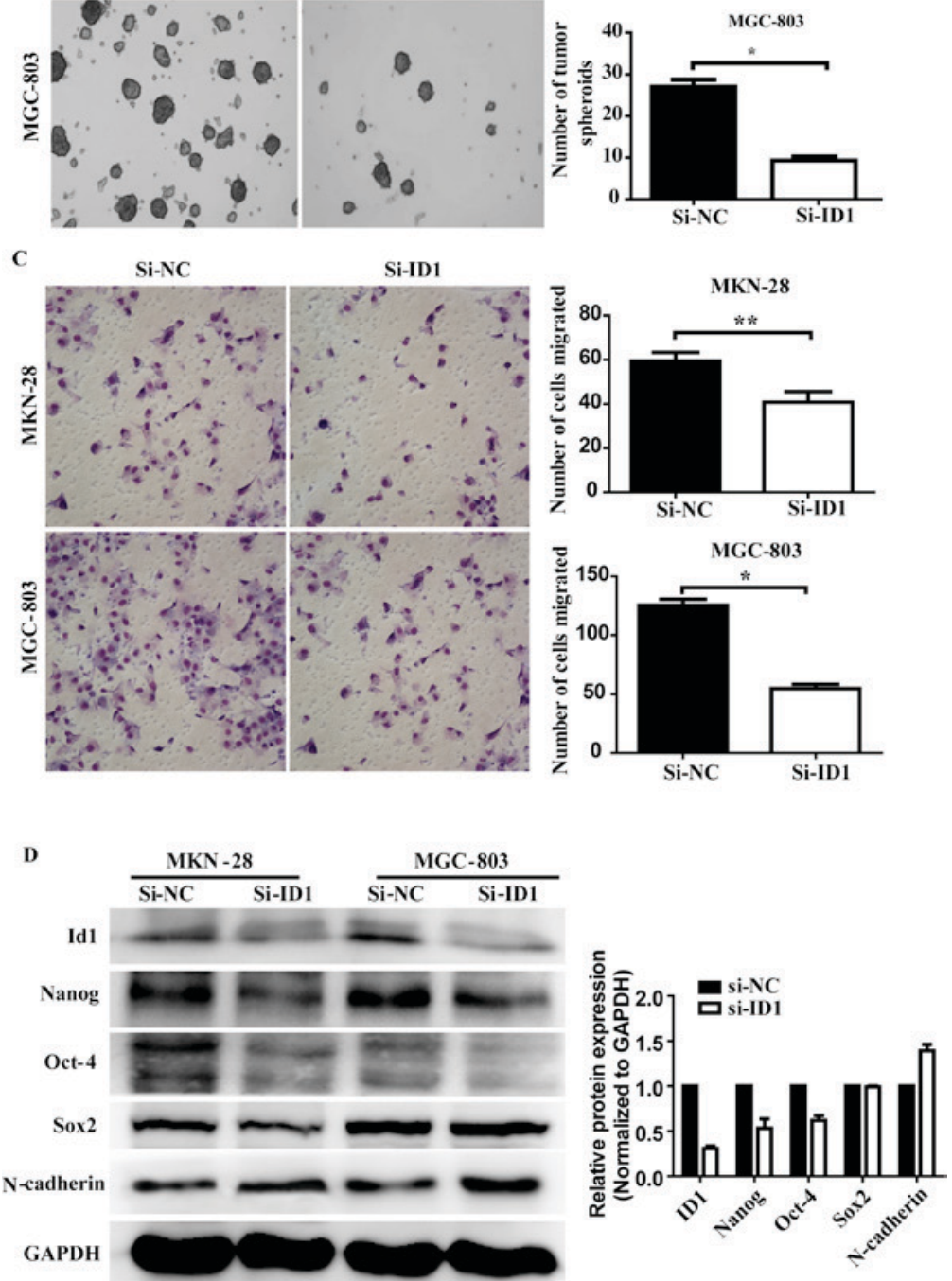

Figure 3. ID1 knockdown decreases the cancer stem cell-like properties of gastric cancer cells. (A) Colony formation was significantly decreased in the ID1 knockdown cells compared with the si-NC-transfected cells. (B) Tumor spheroid formation was significantly reduced in cells transfected with si-ID1 compared with cells transfected with si-NC. Images were captured at x200 magnification. (C) Cell migration assays revealed significantly decreased migration in si-ID1-transfected cells compared with si-NC-transfected cells. Images were captured at x200 magnification. (D) Western blotting was performed to detect the effect of ID1 knockdown on Nanog, Oct-4, Sox 2 and N-cadherin protein expression and quantification, $48 \mathrm{~h}$ following transfection. Values are presented as the mean \pm standard deviation of triplicate results. ${ }^{~} \mathrm{P}<0.05,{ }^{* *} \mathrm{P}<0.01$. ID1, DNA-binding protein inhibitor ID-1; si-, small interfering RNA; NC, negative control; Oct-4, octamer-binding protein 4; Sox2, transcription factor SOX2. 
MGC-803, $\mathrm{P}=0.001)$. These results demonstrate that ID1 knockdown leads to a significant reduction in the ability of GC cells to form colonies.

Tumor spheroid formation assays were used to evaluate the self-renewal ability of CSCs in vitro. MGC-803 and MKN-28 cells were transfected with siRNA-ID1 or siRNA-NC on days 1 and 4, respectively. Following an 8-day incubation, the total number of tumor spheroids with a diameter of $>20 \mu \mathrm{m}$ were counted. As shown in Fig. 3B, ID1 knockdown in MKN-28 and MGC-803 cells significantly decreased the number of tumor spheroids (2.70- and 3.33-fold decrease, respectively) compared with the siRNA-NC-transfected cells (MKN-28, $\mathrm{P}=0.021$; MGC-803, $\mathrm{P}=0.037$ ).

ID1 knockdown attenuates CSC-associated EMT properties. CSCs exhibit EMT, which enables metastasis and invasion (32). The results of the cell migration assays performed on siRNA-ID1- and siRNA-NC-transfected cells are shown in Fig. 3C. Significantly decreased migration was observed in the ID1 knockdown MKN-28 ( $\mathrm{P}=0.002)$ and MGC-803 ( $\mathrm{P}=0.015)$ cells compared with the siRNA-NC-transfected cells. $\mathrm{N}$-cadherin protein expression is a key marker of EMT (33). Western blotting demonstrated decreased N-cadherin protein expression in ID1 knockdown cells compared with siRNA-NC-transfected cells (Fig. 3D; left panel), quantification of the mean gray value from MKN-28 and MGC-803 demonstrated the same results (Fig. 3D; right panel). These results indicated that ID1 knockdown inhibits the migratory ability of GC cells.

ID1 knockdown leads to decreased Nanog and Oct-4 protein expression. The effect of ID1 knockdown on CSC-associated proteins in MGC-803 and MKN-28 cells was analyzed using western blotting $72 \mathrm{~h}$ following siRNA transfection. As shown in Fig. 3D, Nanog and Oct-4 protein expression was decreased in ID1 knockdown cells compared with siRNA-NC-transfected cells. Sox 2 protein expression remained unchanged following transfection. These results indicate that ID1 regulates CSC-like properties by targeting Nanog and Oct- 4 .

IDI knockdown reduces $G C$ cell resistance to DDP. Previous studies have confirmed the role of ID1 in the development of resistance to chemotherapy in non-small cell lung cancer cells (21). In addition, ID1 has been demonstrated to contribute to radioresistance in glioblastoma through inhibition of DNA repair pathways (34). The effect of ID1 knockdown on resistance to DDP in the GC cell lines MKN-28 and MGC-803 was examined. Following siRNA transfection, MKN-28 and MGC-803 cells were treated with 1 and $2 \mu \mathrm{g} / \mathrm{ml}$ DDP. siRNA-ID1-transfected MKN-28 cell viability decreased markedly following treatment with $1(62 \%$ decrease; $\mathrm{P}<0.05)$ and $2(75 \%$ decrease; $\mathrm{P}<0.001) \mu \mathrm{g} / \mathrm{ml}$ DDP compared with the siRNA-NC-transfected cells (Fig. 4A). Similarly, treatment with 1 and $2 \mu \mathrm{g} / \mathrm{ml}$ DDP decreased MKN-28 cell viability compared with the untreated cells (Fig. 4A). siRNA-ID1-transfected MGC-803 cell viability decreased markedly following treatment with 1 (44\% decrease; $\mathrm{P}<0.05)$ and 2 (49\% decrease; $\mathrm{P}<0.05) \mu \mathrm{g} / \mathrm{ml}$ DDP compared with the siRNA-NC-transfected cells (Fig. 4A). In addition, treatment with 1 and $2 \mu \mathrm{g} / \mathrm{ml}$ DDP decreased MGC-803 cell viability compared with the untreated cells (Fig. 4A).
Colony formation assays were performed to further evaluate the effect of ID1 knockdown on GC cell sensitivity to DDP. As shown in Fig. 4B and C, MKN-28 colony formation was markedly decreased in the ID1 knockdown cells compared with the siRNA-NC-transfected cells following treatment with $1 \mu \mathrm{g} / \mathrm{ml}$ DDP $(\mathrm{P}<0.01)$. In addition, colony formation was decreased in the DDP treatment groups compared with the untreated groups. Similarly, MGC-803 colony formation was markedly decreased in the ID1 knockdown cells compared with the siRNA-NC-transfected cells, following treatment with $1 \mu \mathrm{g} / \mathrm{ml}$ $\mathrm{DDP}(\mathrm{P}<0.05)$. Furthermore, colony formation was decreased in the DDP treatment groups compared with the untreated groups.

DDP-induced apoptosis in GC cells is enhanced by IDI knockdown. To further investigate the role of ID1 in DDP resistance, the effect of ID1 knockdown and treatment with DDP on apoptosis was analyzed. As shown in Fig. 4D and E, the percentage of apoptotic MKN-28 $(\mathrm{P}<0.001)$ and MGC-803 $(\mathrm{P}<0.01)$ cells was markedly increased following ID1 knockdown compared with the siRNA-NC-transfected cells. In addition, the percentage of apoptotic MKN-28 and MGC-803 cells was markedly increased following combined ID1 knockdown and treatment with DDP compared with ID1 knockdown alone (both $\mathrm{P}<0.01$; Fig. 4E). These results indicate that ID1 knockdown reduces DDP resistance in MKN-28 and MGC-803 cells through the promotion of apoptosis.

\section{Discussion}

Numerous studies have highlighted the complex role served by members of the ID subfamily in mammalian cell fate determination $(21,27,28,34)$. IDs are involved in numerous biological processes, including the inhibition of differentiation, and the maintenance of self-renewal and multipotency in stem cells $(22,23)$. IDs have therefore been implicated in the coordination of cell proliferation and cell cycle progression (9). The present study utilized 4 siRNAs targeting ID1 and validated their ID1 knockdown efficiency at the mRNA and protein level. ID1 knockdown was demonstrated to be sufficient to inhibit the CSC-like properties of the GC cell lines MKN-28 and MGC-803, including self-renewal, colony formation and EMT. In addition, the expression of two key CSC-associated factors, Nanog and Oct-4, was demonstrated to be reduced in siRNA-ID1-transfected cells. Furthermore, ID1 expression was demonstrated to serve a role in cell proliferation and cell cycle progression, which is consistent with the results of these studies. Moreover, ID1 knockdown was demonstrated to decrease DDP resistance in GC cells, suggesting it is a potential therapeutic target for more effective tumor therapy.

Loss of ID1 expression has been demonstrated to decrease self-renewal and differentiation in mouse ESCs through the downregulation of Nanog (35). In the present study, ID1 was demonstrated to serve a role in gastric CSC maintenance of self-renewal and colony formation. In addition, ID1 was demonstrated to decrease the expression of Nanog and Oct-4, thus an association between ID1 and CSC-associated factors has been established. Nanog, a homeodomain protein, was first discovered while screening for self-renewal factors that were able to sustain ESCs lacking the leukemia inhibitory 

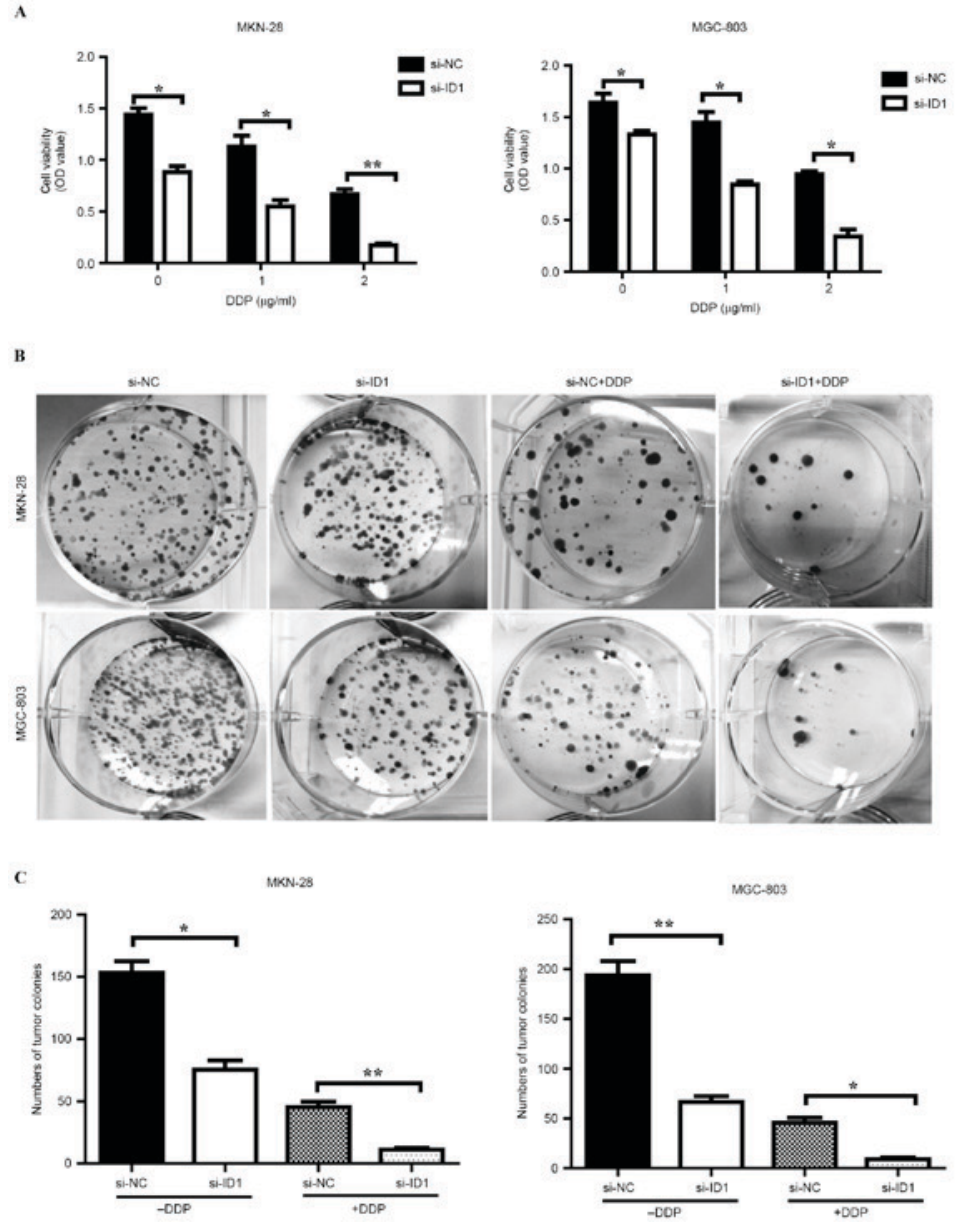

D
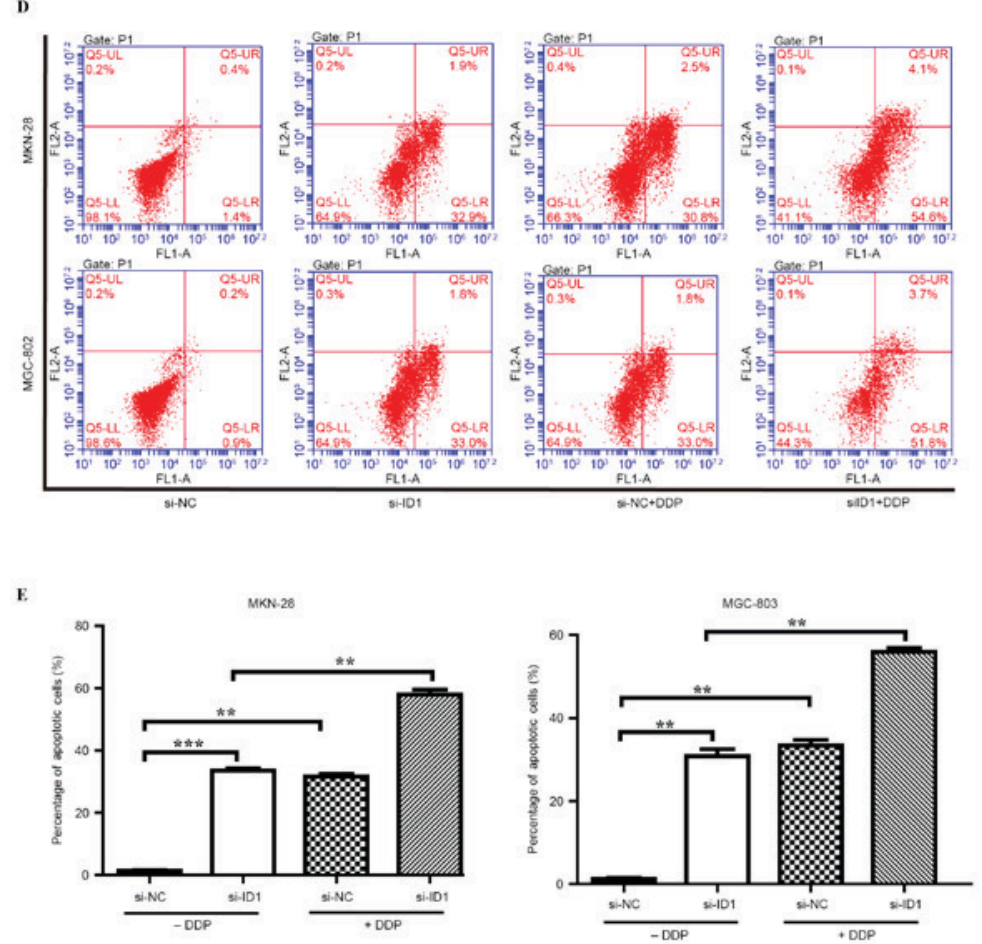

Figure 4. ID1 knockdown sensitizes MKN-28 and MGC-803 cells to DDP. (A) Cells were treated with DDP following transfection with si-ID1 or si-NC. Cell viability decreased significantly following combined ID1 knockdown and treatment with DDP in a dose-dependent manner. (B) Representative images of colony formation following ID1 knockdown and treatment with DDP. (C) Colony formation assay quantification demonstrated a significant decrease in colony formation following ID1 knockdown and treatment with DDP. (D) Flow cytometric analysis of apoptosis following ID1 knockdown and treatment with DDP. (E) The percentage of apoptotic cells increased significantly following ID1 knockdown and treatment with DDP. Values are presented as the mean \pm standard deviation of triplicate results. ${ }^{*} \mathrm{P}<0.05,{ }^{* *} \mathrm{P}<0.01,{ }^{* * *} \mathrm{P}<0.001$. ID1, DNA-binding protein inhibitor ID-1; GC, gastric cancer; DDP, cisplatin; si-, small interfering RNA; NC, negative control; FL, fluorescence; A, area. 
factor signaling pathway (36). As one of the key regulators of the stemness signaling network, which includes Oct-4, Sox2, KLF4 and Myc, Nanog maintains a balance between pluripotency and differentiation (37-39). The expression of Nanog was demonstrated to effect the regulation mouse ESC differentiation, whereby, the downregulation of Nanog results in the differentiation of ESC's into endoderm (40). Nanong is also involved in several tumor development processes, including cellular proliferation, cell cycle progression, apoptosis, metastasis and malignant transformation $(41,42)$. Cross-talk between Nanog and signal transducer and activator of transcription 3, p53 and phosphatase and tensin homolog, account for its role in tumorigenesis (43-45). The association established between ID1 and Nanog in the present study improves the understanding on how the stem cell-like properties of cancer are regulated.

ID1 was reported to induce EMT by promoting transforming growth factor beta-1 expression (29). In the present study ID1 was demonstrated to increase EMT by positively regulating $\mathrm{N}$-cadherin expression, a marker of EMT. This result was confirmed by the reduced migration potential of GC cells following ID1 knockdown. Previous studies have demonstrated that ID1 inhibits GC cell growth through the protein kinase B signaling pathway (46), or by stimulating the expression of cell cycle-associated proteins, including p16, p21, p27 and cyclin D1 (47). In the present study, ID1 knockdown was demonstrated to decrease proliferation and cell cycle progression in MGC-803 and MKN-28 cells.

GC therapy does not typically prevent recurrence, metastasis or the development of multidrug resistance (MDR) (48). The molecular mechanisms underlying MDR involve a series of pathological changes, typically in CSCs. DDP is an important drug used in GC chemotherapy, which functions by inducing DNA damage and mitochondrial-mediated apoptosis (49) Overcoming DDP resistance remains an important challenge in cancer therapy, despite combination therapeutic strategies being developed to combat DDP resistance (50). In the present study, ID1 knockdown in MKN-28 and MGC-803 GC cells was demonstrated to increase DDP sensitivity. These results indicate that ID1 is a novel therapeutic target for the treatment of GC. However, further investigations into the underlying molecular mechanisms of these effects of ID1 are warranted.

In conclusion, the results of the present study establish an association between ID1 and Nanog in the regulation of CSC-likeness in GC cells. Furthermore, ID1 knockdown was demonstrated to significantly increase GC cell chemosensitivity to DDP, which indicates that it is a novel therapeutic target for the treatment of GC. However, the underlying molecular mechanisms through which ID1 regulates Nanog-mediated CSC-likeness remain to be elucidated.

\section{References}

1. Jemal A, Bray F, Center MM, Ferlay J, Ward E and Forman D: Global cancer statistics. CA Cancer J Clin 61: 69-90, 2011.

2. Brawner KM, Morrow CD and Smith PD: Gastric microbiome and gastric cancer. Cancer J 20: 211-216, 2014.

3. Chiu PW, Teoh AY, To KF, Wong SK, Liu SY, Lam CC, Yung MY, Chan FK, Lau JY and Ng EK: Endoscopic submucosal dissection (ESD) compared with gastrectomy for treatment of early gastric neoplasia: A retrospective cohort study. Surg Endosc 26 3584-3591, 2012
4. Kamat AM: Commentary on 'Phase II trial of cetuximab with or without paclitaxel in patients with advanced urothelial tract carcinoma.' Wong YN, Litwin S, Vaughn D, Cohen S, Plimack ER, Lee J, Song W, Dabrow M, Brody M, Tuttle H, Hudes G, University of Pennsylvania, Philadelphia, PA: J Clin Oncol 2012;30(28):3545-51 [Epub 2012 Aug 27]. Urol Oncol 31: 719 , 2013.

5. Siegel R, Ma J, Zou Z and Jemal A: Cancer statistics, 2014. CA Cancer J Clin 64: 9-29, 2014.

6. Perk J, Iavarone A and Benezra R: Id family of helix-loop-helix proteins in cancer. Nat Rev Cancer 5: 603-614, 2005.

7. Benezra R, Davis RL, Lockshon D, Turner DL and Weintraub H: The protein Id: A negative regulator of helix-loop-helix DNA binding proteins. Cell 61: 49-59, 1990.

8. Yates PR, Atherton GT, Deed RW, Norton JD and Sharrocks AD: Id helix-loop-helix proteins inhibit nucleoprotein complex formation by the TCF ETS-domain transcription factors. EMBO J 18: 968-976, 1999.

9. Ling MT, Wang X, Zhang X and Wong YC: The multiple roles of Id-1 in cancer progression. Differentiation 74: 481-487, 2006.

10. Ding Y, Wang G, Ling MT, Wong YC, Li X, Na Y, Zhang X, Chua CW, Wang X and Xin D: Significance of Id-1 up-regulation and its association with EGFR in bladder cancer cell invasion. Int J Oncol 28: 847-854, 2006.

11. Wilson JW, Deed RW, Inoue T, Balzi M, Becciolini A, Faraoni P, Potten CS and Norton JD: Expression of Id helix-loop-helix proteins in colorectal adenocarcinoma correlates with p53 expression and mitotic index. Cancer Res 61: 8803-8810, 2001.

12. Luo KJ, Wen J, Xie X, Fu JH, Luo RZ, Wu QL and Hu Y: Prognostic relevance of Id-1 expression in patients with resectable esophageal squamous cell carcinoma. Ann Thorac Surg 93: 1682-1688, 2012.

13. Yang HY, Liu HL, Liu GY, Zhu H, Meng QW, Qu LD, Liu LX and Jiang HC: Expression and prognostic values of Id-1 and Id-3 in gastric adenocarcinoma. J Surg Res 167: 258-266, 2011.

14. Gautschi O, Tepper CG, Purnell PR, Izumiya Y, Evans CP, Green TP, Desprez PY, Lara PN, Gandara DR, Mack PC and Kung HJ: Regulation of Id1 expression by SRC: Implications for targeting of the bone morphogenetic protein pathway in cancer. Cancer Res 68: 2250-2258, 2008.

15. Lasorella A, Boldrini R, Dominici C, Donfrancesco A, Yokota Y, Inserra A and Iavarone A: Id2 is critical for cellular proliferation and is the oncogenic effector of N-myc in human neuroblastoma. Cancer Res 62: 301-306, 2002.

16. Reynaud-Deonauth S, Zhang H, Afouda A, Taillefert S, Beatus P, Kloc M, Etkin LD, Fischer-Lougheed J and Spohr G: Notch signaling is involved in the regulation of Id3 gene transcription during Xenopus embryogenesis. Differentiation 69: 198-208, 2002.

17. Tam WF, Gu TL, Chen J, Lee BH, Bullinger L, Fröhling S, Wang A, Monti S, Golub TR and Gilliland DG: Id1 is a common downstream target of oncogenic tyrosine kinases in leukemic cells. Blood 112: 1981-1992, 2008.

18. Birkenkamp KU, Essafi A, van der Vos KE, da Costa M, Hui RC, Holstege F, Koenderman L, Lam EW and Coffer PJ: FOXO3a induces differentiation of Bcr-Abl-transformed cells through transcriptional down-regulation of Id1. J Biol Chem 282: 2211-2220, 2007.

19. Paolella BR, Havrda MC, Mantani A, Wray CM, Zhang Z and Israel MA: p53 directly represses Id2 to inhibit the proliferation of neural progenitor cells. Stem Cells 29: 1090-1101, 2011.

20. Ponz-Sarvisé M, Nguewa PA, Pajares MJ, Agorreta J, Lozano MD, Redrado M, Pio R, Behrens C, Wistuba II, García-Franco CE, et al: Inhibitor of differentiation-1 as a novel prognostic factor in NSCLC patients with adenocarcinoma histology and its potential contribution to therapy resistance. Clin Cancer Res 17: 4155-4166, 2011.

21. Hollnagel A, Oehlmann V, Heymer J, Rüther U and Nordheim A: Id genes are direct targets of bone morphogenetic protein induction in embryonic stem cells. J Biol Chem 274: 19838-19845, 1999.

22. O'Brien CA, Kreso A, Ryan P, Hermans KG, Gibson L, Wang Y, Tsatsanis A, Gallinger S and Dick JE: ID1 and ID3 regulate the self-renewal capacity of human colon cancer-initiating cells through p21. Cancer Cell 21: 777-792, 2012.

23. Nam HS and Benezra R: High levels of Id1 expression define B1 type adult neural stem cells. Cell Stem Cell 5: 515-526, 2009.

24. Barrett LE, Granot Z, Coker C, Iavarone A, Hambardzumyan D, Holland EC, Nam HS and Benezra R: Self-renewal does not predict tumor growth potential in mouse models of high-grade glioma. Cancer Cell 21: 11-24, 2012. 
25. Salic A and Mitchison TJ: A chemical method for fast and sensitive detection of DNA synthesis in vivo. Proc Natl Acad Sci USA 105: 2415-2420, 2008.

26. Yin M, Li X, Tan S, Zhou HJ, Ji W, Bellone S, Xu X, Zhang H, Santin AD, Lou G and Min W: Tumor-associated macrophages drive spheroid formation during early transcoelomic metastasis of ovarian cancer. J Clin Invest 126: 4157-4173, 2016.

27. Guo P, Lan J, Ge J, Mao Q and Qiu Y: ID1 regulates U87 human cell proliferation and invasion. Oncol Lett 6: 921-926, 2013.

28. Lai X, Liao J, Lin W, Huang C, Li J, Lin J, Chen Q and Ye Y: Inhibitor of DNA-binding protein 1 knockdown arrests the growth of colorectal cancer cells and suppresses hepatic metastasis in vivo. Oncol Rep 32: 79-88, 2014.

29. Damdinsuren B, Nagano H, Kondo M, Natsag J, Hanada $H$, Nakamura M, Wada H, Kato H, Marubashi S, Miyamoto A, et al: TGF-beta1-induced cell growth arrest and partial differentiation is related to the suppression of Id1 in human hepatoma cells. Oncol Rep 15: 401-408, 2006.

30. Musgrove EA, Caldon CE, Barraclough J, Stone A and Sutherland RL: Cyclin D as a therapeutic target in cancer. Nat Rev Cancer 11: 558-572, 2011.

31. Reya T, Morrison SJ, Clarke MF and Weissman IL: Stem cells, cancer, and cancer stem cells. Nature 414: 105-111, 2001.

32. Ahmad A, Aboukameel A, Kong D, Wang Z, Sethi S, Chen W, Sarkar FH and Raz A: Phosphoglucose isomerase/autocrine motility factor mediates epithelial-mesenchymal transition regulated by miR-200 in breast cancer cells. Cancer Res 71: 3400-3409, 2011.

33. Wells A, Yates C and Shepard CR: E-cadherin as an indicator of mesenchymal to epithelial reverting transitions during the metastatic seeding of disseminated carcinomas. Clin Exp Metastasis 25: 621-628, 2008 .

34. Guo Q, Guo P, Mao Q, Lan J, Lin Y, Jiang J and Qiu Y: ID1 affects the efficacy of radiotherapy in glioblastoma through inhibition of DNA repair pathways. Med Oncol 30: 325, 2013.

35. Romero-Lanman EE, Pavlovic S, Amlani B, Chin Y and Benezra R: Id1 maintains embryonic stem cell self-renewal by up-regulation of Nanog and repression of Brachyury expression. Stem Cells Dev 21: 384-393, 2012

36. Chambers I, Colby D, Robertson M, Nichols J, Lee S, Tweedie S and Smith A: Functional expression cloning of Nanog, a pluripotency sustaining factor in embryonic stem cells. Cell 113 $643-655,2003$

37. Ivanova N, Dobrin R, Lu R, Kotenko I, Levorse J, DeCoste C, Schafer X, Lun Y and Lemischka IR: Dissecting self-renewal in stem cells with RNA interference. Nature 442: 533-538, 2006.
38. Boyer LA, Lee TI, Cole MF, Johnstone SE, Levine SS, Zucker JP, Guenther MG, Kumar RM, Murray HL, Jenner RG, et al: Core transcriptional regulatory circuitry in human embryonic stem cells. Cell 122: 947-956, 2005.

39. Liu L, Wei X, Ling J, Wu L and Xiao Y: Expression pattern of Oct-4, Sox 2 and c-Myc in the primary culture of human dental pulp derived cells. J Endod 37: 466-472, 2011.

40. Mitsui K, Tokuzawa Y, Itoh H, Segawa K, Murakami M, Takahashi K, Maruyama M, Maeda M and Yamanaka S: The homeoprotein Nanog is required for maintenance of pluripotency in mouse epiblast and ES cells. Cell 113: 631-642, 2003.

41. Piestun D, Kochupurakkal BS, Jacob-Hirsch J, Zeligson S, Koudritsky M, Domany E, Amariglio N, Rechavi G and Givol D: Nanog transforms NIH3T3 cells and targets cell-type restricted genes. Biochem Biophys Res Commun 343: 279-285, 2006.

42. Lin YL, Han ZB, Xiong FY, Tian LY, Wu XJ, Xue SW, Zhou YR, Deng JX and Chen HX: Malignant transformation of 293 cells induced by ectopic expression of human Nanog. Mol Cell Biochem 351: 109-116, 2011.

43. Lindgren AG, Natsuhara K, Tian E, Vincent JJ, Li X, Jiao J, Wu H, Banerjee U and Clark AT: Loss of Pten causes tumor initiation following differentiation of murine pluripotent stem cells due to failed repression of Nanog. PLoS One 6: e16478, 2011.

44. Bourillot PY, Aksoy I, Schreiber V, Wianny F, Schulz H, Hummel O, Hubner N and Savatier P: Novel STAT3 target genes exert distinct roles in the inhibition of mesoderm and endoderm differentiation in cooperation with Nanog. Stem Cells 27: 1760-1771, 2009

45. Golubovskaya VM: FAK and Nanog cross talk with p53 in cancer stem cells. Anticancer Agents Med Chem 13: 576-580, 2013.

46. Yang G, Zhang Y, Xiong J, Wu J, Yang C, Huang H and Zhu Z: Downregulation of Id 1 by small interfering RNA in gastric cancer inhibits cell growth via the Akt pathway. Mol Med Rep 5: 1075-1079, 2012

47. Ciarrocchi A, Jankovic V, Shaked Y, Nolan DJ, Mittal V, Kerbel RS, Nimer SD and Benezra R: Id1 restrains p21 expression to control endothelial progenitor cell formation. PLoS One 2: e1338, 2007.

48. Zhang D and Fan D: Multidrug resistance in gastric cancer: Recent research advances and ongoing therapeutic challenges. Expert Rev Anticancer Ther 7: 1369-1378, 2007.

49. Jamieson ER and Lippard SJ: Structure, recognition, and processing of cisplatin-DNA adducts. Chem Rev 99: 2467-2498, 1999.

50. Galluzzi L, Senovilla L, Vitale I, Michels J, Martins I, Kepp O, Castedo M and Kroemer G: Molecular mechanisms of cisplatin resistance. Oncogene 31: 1869-1883, 2012. 